\title{
AN AID TO THE TEACHING OF GEOGRAPHY.
}

\author{
By EDward King, \\ Wimbledon College, Wimbledon, England.
}

Perhaps the results of our experience in the teaching of geography will be of assistance to some of your readers, who, of course, have had the same difficulties which my colleagues and I have encountered in dealing with a difficult subject. We found, as others have done, that wall maps, named and coloured in the ordinary way, were not altogether satisfactory, and, therefore, after one or two preparatory experiments had been made, we adopted the following method of constructing the maps for ourselves.

The Educational Supply Association provides a species of dark green linoleum, which is specially prepared for use with blackboard chalk. The outlines have first to be copied from existing maps by means of tracing paper; the back is then rubbed over with white chalk, so that, when placed upon the linoleum - "Cretaline" the makers call it-and the lines retraced with pencil, a delicate chalk impression is left. This line has only to be painted in with a fine paint brush in white oil paint, and the map is ready for use.

So much for construction; and now one word on its advantages. A pupil can be brought out to the map, provided with a piece of chalk, and told by his teacher to trace out the course of this or that river, the line of a mountain range, or the trade route from Liverpool to New Zealand or Hong Kong. Or, again, with a map of England, the railway systems can be shown in various colours, centers of iron, wool, or cotton industries can be appropriately indicated, all with a lucidity, which it is impossible to obtain from the ordinary wall map. Add to this the moral effect produced on the youthful imagination by the sight of the world on Mercator's Projection, six feet by five, upon which he has to display his geographical knowledge ; and this, not in the privacy of a written examination, but before a critical set of youngsters of his own age and attainments, each one of whom is thirsting to correct the slightest error made by his classnate at the map, and you have at once an enthusiasm created which, though not all, is at least an important factor in the successful teaching of geography.-School World. 